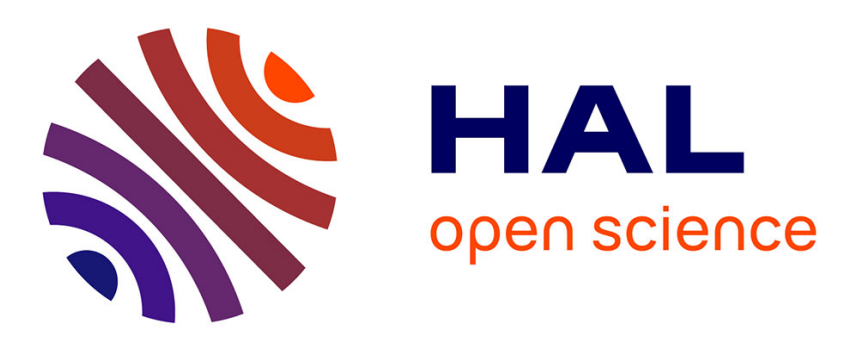

\title{
Recommendation of RILEM TC 241-MCD on Interface Debonding Testing in Pavements
}

Christophe Petit, Armelle Chabot, Alexandra Destree, Christiane Raab

\section{To cite this version:}

Christophe Petit, Armelle Chabot, Alexandra Destree, Christiane Raab. Recommendation of RILEM TC 241-MCD on Interface Debonding Testing in Pavements. Materials and structures, 2018, 51, pp.article 96. 10.1617/s11527-018-1223-y . hal-01836370

\section{HAL Id: hal-01836370 https://hal.science/hal-01836370}

Submitted on 16 Jul 2018

HAL is a multi-disciplinary open access archive for the deposit and dissemination of scientific research documents, whether they are published or not. The documents may come from teaching and research institutions in France or abroad, or from public or private research centers.
L'archive ouverte pluridisciplinaire HAL, est destinée au dépôt et à la diffusion de documents scientifiques de niveau recherche, publiés ou non, émanant des établissements d'enseignement et de recherche français ou étrangers, des laboratoires publics ou privés. 


\title{
Recommendation of RILEM TC 241-MCD on Interface Debonding Testing in Pavements
}

\author{
C. Petit $^{1}$, A. Chabot $^{2}$, A. Destrée ${ }^{3}$, C. Raab $^{4}$ \\ 1 Université de Limoges, France - christophe.petit@unilim.fr \\ 2 IFSTTAR / MAST, France \\ 3 Belgian Road Research Centre (BRRC), Brussels, Belgium \\ 4 EMPA, Swiss Federal Laboratories for Materials Science and Technology, \\ Switzerland
}

\begin{abstract}
:
The following recommendations are based on the chapter III of a State of the Art review conducted by the Task Group 2 of the RILEM Technical Committee 241MCD "Mechanisms of cracking and debonding in asphalt and composite pavements"' (Petit et al in Mechanisms of cracking and debonding in asphalt and composite pavements. Chapter III of the State-of-the-Art report of the RILEM technical committee 241-MCD series, vol 28. Springer, New York, pp 103-154. ISBN 978-3-319-76848-9 2018). The recommendations mostly concern "pure" fracture mode test methods that are currently used worldwide and even standardized, while mixed mode test methods developed by few research teams have not received full attention. This paper intends to give guidance for the application and characterization of interlayer bond testing, looking at the appropriate test methods and the importance of influencing parameters.
\end{abstract}

Keywords: Debonding, interface, pavement, interlayer bond tests

This recommendation was prepared by the task group 2 (TG2) within RILEM TC 241-MCD (2011-2017) consisting of R. Botella, W.G. Buttlar, A. Chabot, A. Destrée, G. Graziani, F. Hammoum, M. Hun, A. Millien, C. Petit, C. Raab, G. Tebaldi, A. Toumi, A. Turatsinze, A. Zofka. The draft recommendation was submitted for approval to the TC members during the TC closure meeting in Nottingham on October $4^{\text {th }}, 2017$ and subsequently approved by the RILEM TC241-MCD (see the list below).

Chairman: William G. Buttlar, University of Missouri, USA

Secretary: Armelle Chabot, IFSTTAR / MAST, France

TG2 leader: Christophe Petit, Université de Limoges, France

TC Members (depending of years between 2011 and 2017): G. Airey, Apeagyei

A., B. Behnia, Bodin D., R. Botella, A. Cannone-Falchetto, O. Chupin, A. Collop, E. Dave (TG1 leader), A. Destrée, H. Di Benedetto, F. Dubois, A. Graziani, J. Grenfell, F. Hammoum, P. Hornych, M. Hun, Jelagin D., N. Kringos, A. Loizos, P. Marsac, A. Millien, F. Moreno, M.L. Nguyen, J. Pais, C. Raab, C. Sauzeat, J.M. Simonin, G. Tebaldi (TG3 leader), A. Toumi, A. Turatsinze, A. Zofka. 


\section{Scope}

Performance and durability of multi-layered pavements strongly depend on the bond between the individual layers and due to stress concentration, a solid bond between surface layers is extremely crucial. Further, there are a number of pavement types with layers constructed of different materials for which the quality of the interlayer bond has been determined essential for avoiding premature distresses such as corrugation, peeling, slippage or fatigue cracking. This recommendation paper lists the most interesting bond testing methods with their main related advises. According to some of these procedures that are mostly standard methods, practical recommendations in term of temperature condition, specimens' size, number of specimen, etc are given. In a last part recommendations for further developments and research are listed.

\section{Lists of abbreviations}

ASTRA

AST

CSIC

DIC

DST

LAMI

LCB

LISST

LPDS

NDT

OFTT

SBT

TBT

TNBT

UTW
Ancona Shear Testing Research and Analysis

Advanced Shear Tester

Composite Specimen Interface Cracking test

Digital Image Analysis

Double Shear Test

Layer Adhesion Measuring Instrument

Laboratorio de Caminos de Barcelona shear test

Louisiana Interlayer Shear Strength Tester

Layer-Parallel Direct Shear

Non Destructive Test

Oregon Field Torque Tester

Shear Bond Test

Tensile Bond Test

Tensile Notch Bond Test

Ultra-Thin White-topping

\section{Main factors influencing interlayer strength}

A first step for more durable pavements is to improve the mechanical performance of interfaces between surface layer and base layer, which are highly submitted to various normal and shear stresses (Figure 1).

During recent decades, in order to try to give answers of how to determine and improve bonding or modified performance, many interlayer bond tests have been developed in various loading conditions [4-13]. However, interface behaviour 
between layers is not yet well understood. To investigate the mechanisms of debonding that often occur in pavement structures, different parameters have to be considered [1][14-19].

(a)

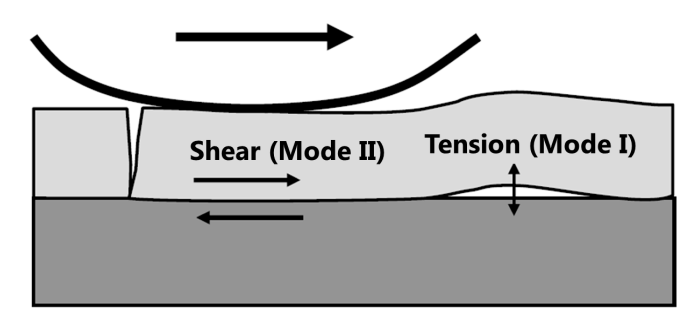

(b)

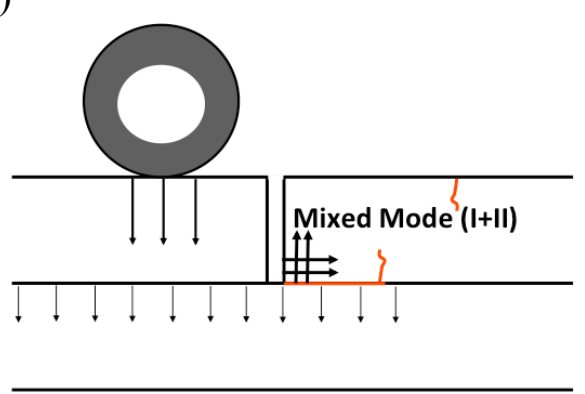

Figure 1: Pavement interface fracture debonding modes (a) far from a vertical crack [2]; (b) at the edge of a vertical crack [3]

Obviously, the mechanical behavior of the pavement materials such as the effect of the viscoelasticity linked to temperature, traffic speed and load (which has not to be considered in a simple way in terms of frequency-dependence conditions for laboratory tests) may have an influence on the interlayer bonding.

Further, environmental effects such as temperature and moisture content of the materials need to be taken into account. In this context, water may play a huge role for interface bonding performance and pavement life, especially when layers show cracks and deficiencies. This fact has been demonstrated for concrete pavements (Figure 2a) [20-21] but it is also true for asphalt pavements (Figure 2b) [22].

(a)

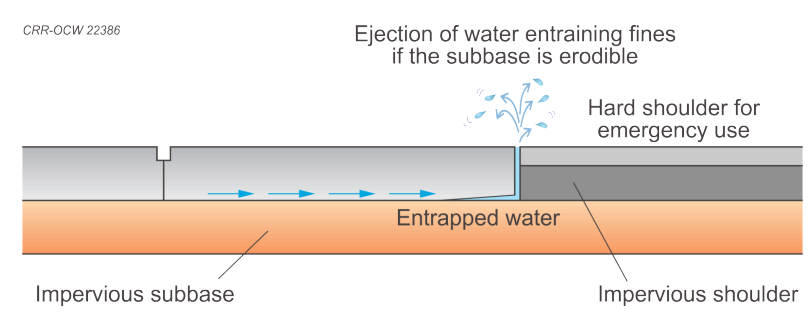

(b)

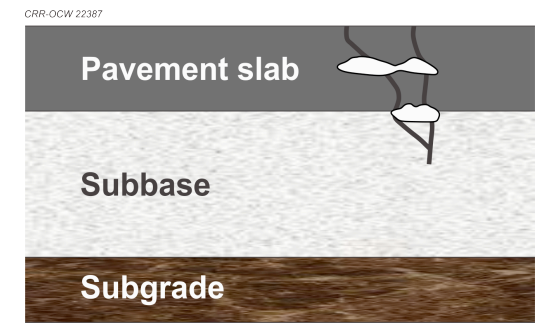

Figure 2: Water propagation in pavements from the top and its effect on interface bonding (a) (from [21]); (b) (from [22])

Physical interface conditions such as cleanliness and roughness conditions are another important aspect and may lead to very various interlocking situations.

When a tack coat is applied, its intrinsic characteristics (viscosity, breaking index, binder content and the characteristics of the residual binder) play an important role for the adhesion between layers and their type and conditions of application such as application rate, curing time or protection technique are equally crucial [11][16].

The size of the specimens for laboratory testing has to be taken into account in the interpretation of the results and as stated by many researchers a large number of specimens is needed before final conclusions can be made (see for example [23]). 
A challenge for design tools regarding the new developments is to include thin surface layer damage and/or structural discontinuities. ...

Although, the influence of certain parameters is still under debate and different opinions of researchers and national requirements exist, during recent years a common knowledge base on interlayer bonding has been established [8]. For laboratory testing there are already some existing technics, that enable the user to get more accurate results and to deepen the knowledge of debonding mechanisms such as the used of Digital Image Correlation (DIC) technics. The task group 2 (TG2) of the RILEM TC241 - MCD has proposed to class the existing interlayer adhesion tests into four categories:

- Mode I: Opening mode

- Mode II: In plane shear mode

- Mode III: Out of plane shear mode

- Mixed Mode: Combination of modes I and II

The following paragraphs give the recommendations that can be drawn for each of the proposed interface bond characterization tests that have been collected in the Chapter III of the State of the Art of the RILEM TC241-MCD [1].

\section{Mode I: Opening mode}

Interface Mode I opening mode is a debonding or an interface damage phenomenon created by means of a tension loading. Two main types of Mode I tension loading devices have been developed: Tensile Bond Tests (TBT), without notch and Tensile Notch Bond Tests (TNBT) with initial notch.

The Tensile Bond Test (TBT) [17, 25-27]:

These tests use specimens without notch and can be applied to assess the capability of tack coats as well as the internal cohesion of the two involved pavement layers. The TBT can be carried out both in situ and in laboratory. These devices mainly differ in the specimen's geometry (cubical - size between $80 \times 80$ $\mathrm{mm}$ and $100 \times 100 \mathrm{~mm}$ - or cylindrical - maximum diameter $150 \mathrm{~mm}$ ), tensile rate (in $\mathrm{mm} / \mathrm{min}$ or $\mathrm{N} / \mathrm{s}$ ) and the way the test specimens are held (gluing, gripping or clamping). The standard test is usually stress-controlled by applying a tensile force (maximum $200 \mathrm{~N} / \mathrm{s}$ ) until failure. In these standard methods, the estimation of tensile bond strength in obtained by help of three specimens for thin wearing courses (thickness $\geq 30 \mathrm{~mm}$ ) while six specimens are needed for ultra-thin wearing courses (thickness $\leq 20 \mathrm{~mm}$ ). For cubical specimens, the tensile load is applied in a low displacement-controlled mode until the specimen fails.

- Care needs to be taken regarding the adhesive (glue) used to hold the specimen in the tensile device; it should be suitable to avoid failure in the adhesive itself. Here, two-component epoxy glues are recommended.

- Due to the geometry of the tested specimens (cylindrical or cubical), the difficulty of the test is to get uniform tensile stress distribution close to the interface. Shear stresses that exist at the edge of the specimens may affect the results of this "pure" mode I test. The use of specimens with large dimensions as average minimum of six times the maximum size of aggregate is highly recommended. 
- The visual assessment of the specimen after the failure is important. The existing modes of failure can be divided into three categories: cohesive, adhesive or mixed.

- For this kind of test failure does not necessarily occur at the interface because debonding happens at the weakest point which can be within the pavement layers, which is one of the main disadvantages of the testing method. So, the most important limitation of the tensile bond tests is that, if the interlayer bond resistance is higher than the in-layer tensile resistance of the two involved specimen's layers, the test result is lower than the actual interlayer bond strength.

- For tests on specimens prepared in the laboratory, the cubical geometry turns out to be more advantageous for DIC analysis than the cylindrical geometry. However, for tests on samples taken on site, a cubical geometry will cause more damage and subsequently extensive repairs.

- In test method allows situ testing, that means the determination of bond strength directly on site. Before applying the gripper system on the pavement surface and applying a tensile force, a ring-groove is generally made beneath the top layer. This has the advantage that if the bond strength is sufficient (no failure up to a maximum force), the test can be done with limited damage to the pavement layers (only the circular groove formed by the coring remains). Although, in case of failure, the different holes obtained may result in more repairing costs and efforts in comparison with the reparation of a "conventional coring" performed on a greater thickness.

- In comparison with temperature-controlled laboratory conditions, the ambient temperature on site will notably influence the test leading to less precise results. However, for some devices such as LAMI, a correction factor that takes into account the test temperature can be applied in case of on site testing.

The Tensile Notch Bond Test (TNBT) [28-33]

This tests use specimens with an initial notch at the interface between layers with the aim to localize and evaluate its fracture properties. The principle of the TNBT consists on opening a crack in double-layered specimen until a complete separation of the two layers takes place. The devices mainly differ in the specimen's geometry (cut straight faces from cores or cubic specimens to facilitate the use of DIC technics), the size and width of the notch, the magnitude and the modal distribution of loads (by means of glued plates, holes, wedge, ...) on the two involved specimens' layers.

With TNBT devices, the debonding propagation is obtained in a stable way. In static conditions, tests are usually done under displacement-controlled condition (generally less than $2 \mathrm{~mm} / \mathrm{min}$ ). Tests under water bath are also possible. The obtained results are mostly a load - crack opening displacement curve from which different fracture information can be determined: the maximum tensile stress before the debonding; the fracture energy value; the slope of the decreasing curve that gives the fracture propagation behavior (brittle or ductile) of the interface. Depending on the devices, these tests can be used for fatigue testing of bi-layered specimens.

- For this test specimens' preparation is more difficult and cumbersome than for other tests such as TBT or SBT. Therefore, it is absolutely necessary to pay attention to both the specimen and the notch preparation.

- A large number of specimens must be tested per type of thermal and loading conditions (no less than 10 tests) have to be conducted before concluding on results in terms of fracture energy. 
- Compared to tests on cores, the TNBT test offers the possibility to separate large interface planes which may be very convenient for testing the bond between grids (with large meshes) and asphalt. In order to precise the debonding results, it is recommended to evaluate the dead weight contribution of specimens with large dimensions.

\section{Mode II: In plane shear mode}

Interface Mode II in plane shear mode is a debonding or an interface damage phenomenon created by means of a shear loading. The shear tests are inspired by shear testing in soil mechanics. It is a well-known fact that the shear test suffers from insufficiencies, since the specimen is subjected not only to shear, but a bending moment is introduced due to an eccentric load induction. Many different types of shear test equipment have been developed in different countries and they can be classified into two categories: pure direct shear tests (without normal stress) and direct shear tests (with normal stress).

In order to introduce the effect of traffic loading some shear testing devices allow the application of a normal load. Equipment with (AST, ASTRA, LISST) or without (Leutner, LPDS, LCB) normal stress are used.

The Shear bond test (SBT) without normal stress [2, 8-10, 25, 34-40]

In general, the SBT is a guillotine type test where the shear force is induced directly at one side and not induced at the front surface of the specimen. The test is mostly done on cylindrical specimens extracted from the pavement or prepared in laboratory (LPDS, LCB,...). Mainly two diameters are usually used $100 \mathrm{~mm}$ and $150 \mathrm{~mm}$. Otherwise the Double Shear Test (DST) is done on parallelepipedic samples. As for the influence of the diameter, it is found that the maximum shear stress values for all temperatures tested with cores of $150 \mathrm{~mm}$ diameter are lower than the results of the test carried out with $100 \mathrm{~mm}$ asphalt cores. The direct shear testing devices can be divided into devices which use a clamping or fitting system to hold the test specimen [39, 41-42] and devices which use a bending mechanism (three or four point shear tests) to apply the shearing [37]. The gap width between the shearing rings is an important variable, which cannot be neglected. For the test conducted by displacement controlled at a rate of $(50 \pm 2) \mathrm{mm} / \mathrm{min}$, the European prenorm [25] recommends a gap width between the shearing rings $\leq 5 \mathrm{~mm}$ ). The obtained result is a shear force versus shear displacement graph that allows the calculation of the maximum shear stress, the shear stiffness modulus and the determination of the shear energy. The latest is determined from the area below the shear force-deflection graph as measured between the displacement at maximum shear stress and the intersection of the linear shear force slope with the displacement-axis in (in Nm). The DST allows the investigation of interface behavior in shear monotonic, cyclic and fatigue loading, under controlled temperature and frequency conditions. Fatigue law parameters can be identified $[7-8,38]$.

The Shear bond test (SBT) with normal stress [40, 43-44]

Many researchers argue that the normal stress, representing the wheel load on the road, has to be included in interlayer bond testing. Regarding its influence (e.g. the magnitude of normal stress) different opinions and findings are being discussed [34, 42]. The application and influence of normal stress is one of the issues, which have been under debate for quite some time. Many of the current 
designs for shear strength testing equipment produce highly variable results or require complex bi-axial load frames. The so-called LISST uses cylindrical specimens of either $100 \mathrm{~mm}$ or $150 \mathrm{~mm}$ diameter with a constant rate of 2.54 $\mathrm{mm} / \mathrm{min}$, a normal load and possible normal forces. The gap between the shearing and the reaction frame measures $12.7 \mathrm{~mm}$. In the current AST version, specimens of $150 \mathrm{~mm}$ diameter are tested. The gap size can vary incrementally between 5 and $12 \mathrm{~mm}$, which may influence the results [9]. The system allows for various combinations of the static and cyclic loading conditions in the load- or displacement-control mode to be applied to specimens across various temperature conditions.

- Standard tests (SBT) such as Leutner enable the user to determine shear bond performance at a predefined plane and they are very easy to conduct. SBT is a valid method for quality control, but only investigates interlayer bond properties at failure. Further, the testing method does often not consider the application of a normal stress as represented by tire forces on the road. When looking at the interlayer bond properties during the service life of a pavement cyclic testing is recommended. Here, the link between bonding properties and changing temperature effects, rest periods or healing phenomena can be evaluated. Cyclic shear bond results can further be used for interlayer bond performance prediction and modeling purposes.

- Regarding specimens size, greater core diameters of $150 \mathrm{~mm}$ or preferable to $100 \mathrm{~mm}$ especially for larger maximum aggregate sizes.

- Gap width is very important: A big gap width will lead to an increased eccentricity resulting in a combined bending-shear stress situation and greater scattering of results. While on the other hand the gap width has to be big enough to account for layers with bigger maximum aggregate sizes and layers with evenness irregularities. Although, European standards allow a gap width between 0 and $5 \mathrm{~mm}$, research (Raab et al. 2010) revealed that a gap width between the shearing rings of ca. $3 \mathrm{~mm}$ seems to be optimal regarding the above mentioned criteria.

- Tests conducted in different laboratories have also shown that, for especially for certain constructions such as ultra-thin top layer, a minimum of 6 specimens should be taken for the determination of the average shear bond strength $[8,36$, 54].

\section{Mode III: Out of plane shear mode}

Torque testing is another way to determine the bond between pavement layers and it can be carried out both in situ and in laboratory [40-41, 45-46]. Torque testing allows the determination of the torque bond strength between a top layer and the bottom layer. Depending on the working method, the torque is applied until failure occurs or a maximum torque is exceeded. Torque test devices are quite similar compared to one another. In principle, they consist of a gripper system that is glued or fixed to the test specimen and a torque cell applying the torque moment. Torque devices mainly differ in the way the test specimens are held (gluing, gripping or clamping) and in the construction of the test frame (manual or automatic torque devices). The test specimens for laboratory testing are generally cores with diameters of $100 \mathrm{~mm}, 150 \mathrm{~mm}$ or $200 \mathrm{~mm}$ (depending on the top layer thickness or the torque test device). 
- Torque testing provides a non-uniform shear stress distribution, varying between zero in the center of the interface cross section to a maximum value at its outside.

- Unlike the direct shear testing, the torque testing induces shear stresses at the interface as well as in the surface course of the specimen. The torsion test is therefore less precise than the shear test and also more difficult to interpret in terms of type of failure, since it induces both a torque at the interface and in the upper layer itself, unlike the shear test which concentrates the shear loading exclusively on the interface [54].

- Since specimens have to be fixed in the torque devices (gluing, gripping or clamping) special care should be taken regarding the fixing mechanism:

- Adhesives (glue) should be suitable to avoid adhesive failure (partly or completely in the adhesive). Here, again two component epoxy glues are recommended.

- Gripper systems should hold the specimen strongly and correctly to avoid slippage or deformation of the specimen.

- In comparison with the direct shear testing, the torque bond test would be less suitable for laboratory based routine testing of interlayer bond properties because it typically requires fixing the specimen (gluing, gripping or clamping).

- Despite the cumbersome handling, torque testing offers a good possibility for in situ testing and testing of thin surfacing.

- Although in comparison with well-controlled laboratory conditions, the temperature dependence of the torque bond strength on site will notably influence the test result and has to be taken into consideration regarding precision of the test.

- The torque testing has the disadvantage that it is generally performed manually. This requires a certain degree of experience and strength. In fact, it is difficult to keep the application of torque parallel to the interface resulting in axial bending on the specimen and it is sometimes physically difficult to exceed high torque bond strength.

- The weak precision of the manual torque test devices might be a result of the variability and bias introduced by the manual load application. The difficulty of maintaining a constant torque rate manually is one of the reasons why several researchers decided to develop automatic torque devices. The OFTT is one of these automatic in-situ torque devices; it is used in the United States of America to evaluate the long-term post-construction tack coat performance of pavement sections.

- As opposed to the similarity in torque device construction, the torque test protocols generally offer a great variability, which does not simplify the comparison between different tests. This is a fact, which made it impossible to conduct interlaboratory testing in the same manner as for shear or pull-off testing [8].

- As for the tensile bond test, failure occurs not necessarily at the interface because the debonding happens at the weakest point, which might be within the pavement layers. This means, that if the interlayer bond resistance is higher than the in-layer tensile resistance of the involved interface, the test result does not represent the actual interlayer bond strength. 


\section{Mixed Mode: Combination of modes I and II}

Some results from the field lead to the conclusion that the interface fracture mode type may not be pure especially near existing vertical cracks through a layer thickness (Figure 1). Three different fracture tests have been proposed by the TG2 researchers of the TC 241-MCD to investigate different questions of interface bonding (behavior) in mixed mode fracture conditions on several type of bimaterial layers [1]. First in order to study the durability of thin bonded cement based repairs, a three point bending (static and cyclic) test is used and modelled [47 - 48]. This test allows the modelling analysis of the influence of major parameters (such as shrinkage, moisture diffusion, fibre reinforcement, and overlay with low rigidity) on the durability of concrete-concrete bi-layer composites [49]. Secondly, to investigate the characterization of the crack initiation and propagation at the interface between layers of composite pavements such as UTW, a four-point bending test has been adapted to pavement materials [50-51]. Under displacement controlled conditions, the study of water effect on the bond characterisation, as observed in real roads [52] is possible with help of DIC analysis and a water bath in which the specimens are tested [15]. Finally, a third test, called a composite specimen interface cracking test (CSIC), has been designed in order to study the optimization of tack coat and application rates [53]. A hole in the center of the two layers specimen bonded by a tack coat serves both as a stress concentrator to initiate cracking (top-down or reflective) and as a platform for load application. The developed system involves repeated tensile loading and monitoring of number of cycles to failure.

For the evaluation of the performance of the mixed mode tests proposed compared to standard ones, two main following recommendations are given here. It aims to also serve the understanding of debonding mechanisms in pavements.

- The possibility to separate both fracture modes of samples submitted to mixed mode loading is the main objective. At the end, an analysis is expected on the comparison on the results of these mixed-mode tests with the tests conducted in "pure" opening or "pure" shear mode.

- Combined to advanced modelling, advance measurements technics such as the use of DIC technics are a need for separating these different fracture modes.

\section{Conclusions}

Interlayer bond testing allows for a great variety of devices and methods. The choice of one or the other does certainly depend on the existing failure mechanism, the purpose of testing (quality control, determination of material property or influencing factor such as moisture, type of tack coat etc.), the situation of testing (in situ or in laboratory), the kind of material tested (thin surfacing, composite material) and many more. In this recommendation paper, practical recommendations for the main standard methods are listed as follows:

- Since shear mode appears to be the most common cause of interlayer bond failure, shear testing (in plane shear mode) -also because of its fairly simple handling and the fact that the shear plane is predefined- is recommended for quality control. 
- It has been shown that for interlayer bond testing the amount of specimens should not be too small; for determining mean values in quality control 4 specimens seem reasonable while for research and interlaboratory testing a minimum of 6 specimens is required.

- Further, the diameter of test specimens should be preferably $150 \mathrm{~mm}$ compared to $100 \mathrm{~mm}$, it has to be at least 6 times the nominal maximum aggregate size.

- When looking at the gap width of the shearing rings a size between $2 \mathrm{~mm}$ and $3 \mathrm{~mm}$ was found suitable.

- It is generally known, that interlayer bonding is highly dependent of temperature, test speed and load (static, cyclic, application of normal load) dependent especially when testing asphaltic materials. Therefore, it is absolutely necessary to take these factors into consideration when discussing test results and outcomes. Although, high temperatures are more critical for the debonding of layers, standard test should be performed at a medium temperature of $20^{\circ} \mathrm{C}$.

- In situ testing is done preferably using torque or pull-off testing. Here, temperature dependency has to taken into account. These two types of test also offer a great potential for interlayer bond testing of thin surfacing.

- Due to the gluing

For the evaluation of material properties and interlayer bond characteristics cyclic testing which does not only evaluate interlayer bond at failure is recommended.

Regarding the further development of interlayer bond testing, it is crucial to improve the phenomenological understanding of the mechanisms and influencing parameters in interlayer bond testing [14].

According to the State of Art Review conducted by the TG2 of the Rilem TC241 MCD [1], various deficiencies for studying different parameters have been highlighted. Therefore, future developments and research needs are recommended below.

1. Moisture /water effect infiltration through cracks and other pavement defects have a big influence on the quality of interlayer bond. Moisture was found to reduce the bond strength drastically [15, 18, 39]. Its effect should be investigated in more detail and moisture should be integrated in the standard methods and considered in pavement design tools.

2. Need to improve the phenomenological understanding of the mechanisms of interlayer bonding in terms of roughness and the geometrical surface conditions of the interface. In this context the use of model materials [19, 55], and finite element modeling as well as roughness measurements at the interface [17] could be very important and useful. These parameters have to be introduced in the standard methods and pavement design tools.

3. Size effect: The specimen size is of great importance for the outcome of interlayer bond testing. As demonstrated by an interlaboratory test program initiated by RILEM [8] the specimens with smaller diameters were found to achieve higher bond values compared to specimens with smaller diameters. Further, the bigger nominal aggregate size or mesh size (when testing pavements with reinforcing interlayers), the bigger the test specimen should be. In that case the dead weight contribution of the specimen- might has to be taken into account.

4. Temperature effects have to be studied in more detail. On the one hand shear bond decreases with the increasing temperature, on the other hand increasing 
temperature may influence the bond positively in terms of healing due to increasing binder viscosity and the compaction effect of traffic. It was further found that interlayer bond defects or weaknesses seem to appear more obvious when testing is performed at very low temperature of $-20^{\circ} \mathrm{C}[56]$.

5. Need to conduct cyclic and static round robin tests to compare the outcome of different devices and methods in more detail and to develop harmonized testing procedures and requirements.

6. Need to compare laboratory results with in situ experiences. Since severe differences between laboratory results and field performance have been identified it appears necessary to define reasons (e.g. ideal laboratory specimens versus real field and construction conditions; laboratory testing versus in situ load application) and modify laboratory testing where required. One way to do so is to test specimens coming from the field and compare the results with those from real scale accelerated loading experiments [33].

7. Need to use energy approaches for modelling interface damage with the aim of quantifying damage evolution during testing. The introduction of rest periods during cyclic will enable the user to assess healing properties and potential.

8. Need to test enough specimens according to the selected type of test and the applied test conditions (for static and cyclic).

9. Need to improve knowledge with advance measurement systems such as:

- $\quad$ NDT (Non Destructive Technics) for field experiment.

- Sensors for the determination of in situ interface bond (shear) values.

DIC (Digital Image Correlation) technics for laboratory tests. The local analysis close to the interface area by means of DIC technics. In particular the DIC technics allow the local analysis close to the interface area by means of the measurement of displacements directly above and below the interface. It may help to access the interface mechanical behavior and some of the above parameters [24] facilitating a more accurate analysis of debonding mechanisms and interface behavior.

Acknowledgments Thanks to O. Abraham, F. Canestrari, F. Fouchal, A. Guarin, K. S. Hakimzadeh, B. Hill, F. Lebon, R.B. Miro, F.E. Pérez-Jiménez, J.M. Piau, B. Picoux, C. Plati, O. Pop, R. Roque, C. Sullivan and M. Takarli for their contributions in the Chapter III "Interface debonding behavior" of the MCD STAR document from which a part of this recommendation has been provided.

\section{Compliance with ethical standards}

Conflict of interest The authors declare that they have no conflict of interest.

\section{REFERENCES}

[1] Petit C., Chabot A., Destree A., Raab C., 2018. Interface debonding behaviour. In Buttlar W.G., Chabot A., Dave EV., Petit C., Tebaldi G. (Eds) Mechanisms of Cracking and Debonding in Asphalt and Composite Pavements. Chapter III of the State-of-the-Art Report of the RILEM Technical Committee 241-MCD Series, Vol. 28: 103-154, Springer International Publishing, ISBN 978-3-319-76848-9

[2] Raab, C., Partl, M. N. (2004) Interlayer shear performance: experience with different pavement structures. In the Proceedings of the 3rd Eurasphalt \& Eurobitume Congress, Vienna, Austria, 12-14 May, 1: 535-545. ISBN 90-802884-4-6 
[3] Chabot, A. \& Tran Q. D. \& Ehrlacher A. (2007) A modeling to understand where a vertical crak can propagate in pavements. In Taylor \& Francis Group Proceedings, Internat. Conf. on Advanced Characterization of Pavement and Soil Engineering Materials, Athens June 20-22 2007, 1: 431-440. ISBN 10: 0415448824

[4] Brown SF, Brunton JM (1984) The influence of bonding between bituminous layers. Highways Transp 31(5): 16-7

[5] Vanelstraete A., Francken L. (1997) State-of-the-Art Report of RILEM Technical Committee 157 PRC, Systems to prevent Reflective Cracking in Pavements, Edited by A. Vanelstraete and L. Francken, RILEM REPORT 18.

[6] Pouteau B., Balay J.-M., Chabot A., De Larrard F. (2004) Fatigue test and mechanical study of adhesion between concrete and asphalt. 9th Int. Symp. on Concrete Roads, 3-6 April, Istanbul, Turkey

[7] Diakhaté M., Phelipot A., Millien A., Petit C. (2006) Shear fatigue behavior of tack coats in pavements. Road Materials and Pavement Design 7(2): 201-222

[8] Piber, H., Canestrari, F., Ferrotti, G., Lu, X., Millien, A., Partl, M.N., Petit, C., PhelipotMardelle, A., Raab, C. (2009) RILEM Interlaboratory Test on Interlayer Bonding of Asphalt Pavements. 7th Int.RILEM Symposium ATCBM09 on Advanced Testing and Characterization of Bituminous Materials, Rhodes, Greece Volume 2: 1181-1189

[9] Raab, C., Partl, M.N. Abd El Halim A. O. (2009) Evaluation of Interlayer Shear Bond Devices for Asphalt Pavements. Baltic Journal of Road and Bridge Eng. 4(4): 176-195

[10] Partl, M.N., Bahia, H.U., Canestrari, F., de la Roche, C., Di Benedetto, H., Piber, H., Sybilski, D. (Eds.) 2013 Advances in Interlaboratory Testing and Evaluation of Bituminous Materials. RILEM State-of-the-Art Reports of the RILEM Technical Committee 206-ATB, Vol. 9, XII, 453 p.

[11] Destrée A., De Visscher J., Piérard N., Vanelstraete A. (2015) Field study to investigate the impact of conditions of application of tack coats on the interlayer bond strength. 8th International RILEM SIB Symposium, October 7-9, 2015, Ancona Italy.

[12] Destrée A., De Visscher J., Vanelstraete A. (2016) Field study to evaluate different prenormative interlayer adhesion tests. Proceedings of the 6th Eurasphalt \& Eurobitume Congress, p. 11, 1- 3 June 2016 - Prague Congress Centre

[13] Chabot A., Buttlar B., Dave E., Petit C., Tebaldi G. (Eds), (2016) Proc. of the 8th RILEM International Conference on Mechanisms of Cracking and Debonding in Pavements. Springer Series: RILEM Bookseries Vol. 13. doi: 10.1007/978-94-024-0867-6

[14] Chabot A., Petit C. (2017) Mechanisms of Cracking and Debonding in Pavements: debonding mechanisms in various interfaces between layers. European Journal of Environmental and Civil Engineering, 11 (sup1): 1-2. doi: 10.1080/19648189.2017.1361649

[15] Chabot A., Hammoum F., Hun M. (2017). A 4pt bending bond test approach to evaluate water effect in a composite beam. European Journal of Environmental and Civil Engineering, 21 (supp 1): 54-69. doi: 10.1080/19648189.2017.1320237

[16] Destrée A., De Visscher J. (2017) Impact of tack coat application conditions on the interlayer bond strength. European Journal of Environmental and Civil Engineering 21 (supp 1): 3-13. doi: 10.1080/19648189.2017.1285252

[17] Ktari R., Fouchal F., Millien A., Petit C. (2017) Surface roughness: a key parameter in pavement interface design. European Journal of Environmental and Civil Engineering 21 (supp 1): 27-42. doi: 10.1080/ /19648189.2017.1304284

[18] Mateos A., Harvey J., Paniagua F., Liu A.F. (2017) Mechanical characterisation of concrete-asphalt interface in bonded concrete overlays of asphalt pavements. European Journal of Environmental and Civil Engineering 21 (supp 1): 43-53. doi: 10.1080/ 19648189.2017.1311808

[19] Raab C., Arraigada M., Partl N., Schiffmann F. (2017). Cracking and interlayer bonding performance of reinforced asphalt pavements. European Journal of Environmental and Civil Engineering 21 (supp 1): 14-26. doi: 10.1080/19648189.2017.1306462 
[20] BLPC (1979) Concrete pavements : problems raised by the presence of water in their structure (Chaussées en béton : problèmes posés par la présence d'eau dans leur structure). Bulletin de liaison des laboratoires des ponts et chaussées, special issue, 8. (In French)

[21] Fuchs F., Jasienski A. (1997) Le phénomène du "Punch-Out" sur les autoroutes belges en béton armé continu - causes, effets et remèdes. Bulletin from the Federation de l'industrie cimentière Belge and the Centre de Recherches routières Belge (In French) www.brrc.be/pdf/bulletin/bul30t.pdf

[22] Bergeron G., Paradis M., Tourangeau G. (2014) Réparation des nids-de-poule. Info DLC, Bulletin d'information technique, 19 (1) (In French)

[23] Santagata Felice A., Ferrotti G., Partl M.N., Canestrari F. (2009) Statistical investigation of two different interlayer shear test methods. Materials and Structures 42 (6): 705-714

[24] Buttlar W. G., Hill B. C., Kim Y. R., Kutay M. E., Millien A., Montepara A., Paulino G. H., Petit C., Pop I. O., Romeo E., Roncella R., Safavizadeh S. A., Tebaldi G., Wargo A. (2014) Digital image correlation techniques to investigate strain fields and cracking phenomena in asphalt materials. Materials and Structures 47 (8): 1373-1390

[25] prEN 12697-48 (2015) Bituminous mixtures - Test methods for hot mix asphalt — Part 48: Interlayer Bonding

[26] BRRC (2012) MM - MPT - 02.02, Tensile adhesion test, Belgian Road research Centre-BRRC working method for the determination of bond strength to underlayers.

[27] LC 25-010 (2016) Mesure de la force de liaison avec un appareil de mesure d'adhésion des couches. Méthode d'essai LC25-010, Secteur - liants hydrocarbonés, Transports Québec, December 15

[28] Tschegg, E. K. (1986) Equipment and appropriate specimen shapes for tests to measure fracture values, AT No. 390328, Austrian Patent Office, Vienna, Austria

[29] Brühwiler E., Wittmann FH. (1990) The Wedge splitting test, a new method of performing stable fracture mechanics tests. Engineering Fracture Mechanics 35 (1-3): 117-125

[30] ASTM D7313-07a (2008) Standard Test Method for Determining Fracture Energy of Asphalt-Aggregate Mixtures Using the Disk-Shaped Compact Tension Geometry. ASTM Volume 04.03 Road and Paving Materials

[31] Lugmayr, R., Jamek, M., \& Tschegg, E.K. (2009) Mechanism of fatigue crack propagation and fracture behavior in bituminous roads. In A. Loizos, M.N. Partl, T. Scarpas \& I.L. Al Qadi (Eds). Advanced Testing and Characterization of Bituminous Materials (pp. 807816). London: Taylor \& Francis.

[32] Hakimzadeh S., AbayKebede N., Buttlar WG, Ahmeda S., Exline M. (2012) Development of fracture-energy based interface bond test for asphalt concrete. Road Materials and Pavement Design 13 (Sup 1): 76-87

[33] Gharbi M., Nguyen M.L., Trichet S., Chabot A (2017) Characterisation of the bond between asphalt layers and glass fiber grid with help of a Wedge Splitting Test. BCRRA 2017, Athens June 28-30. In CRC Press (Verlag) -Taylor \& Francis Group proceedings: 1517-1524, ISBN: 978-1-138-29595-7. doi: 10.1201/9781315100333-217

[34] Uzan J., Livneh M., Eshed Y. (1978) Investigation of adhesion properties between asphaltic concrete layers. Asphalt Paving Technology 47: 495-521

[35] Leutner R. (1979) Untersuchung des Schichtverbundes beim bituminösen Oberbau, Bitumen 41 (3): 84-91

[36] Raab,C., Partl, M.N (November 1999). Methoden zur Beurteilung des Schichtenverbunds von Asphaltbelägen. Eidgenössisches Departement für Umwelt, Verkehr, Energie und Kommunikation, Bundesamt für Strassen, Report No 442

[37] Mirò R., Pérez Jiménez F., Borras Gonzalez J. M. (2003) Evaluation of the effect of tack coats. LCB shear test. 6th RILEM Symposium PTEBM ${ }^{\text {ce } 03, ~ Z u r i c h, ~ S w i t z e r l a n d, ~ 550-556 ~}$

[38] Petit C., Diakhaté M., Millien A., Pouteau B. (2009) Pavement Design for Curved Road Sections. Road Materials and Pavement Design 10(3): 609-624.

[39] Partl M.N., Raab C. (1999) Shear Adhesion between Top Layers of Fresh Asphalt Pavements in Switzerland. Proceedings, 7th Conf. on Asphalt Pavements for Southern Africa, CAPSA ‘99, Victory Falls, Zimbabwe, 5.130-5.137 
[40] Raab C. (2010) Development of a Framework for Standardisation of Interlayer Bond of Asphalt Pavements. PhD thesis, Department of Civil and Environmental Engineering, Carleton University, Ottawa, Canada

[41] West R.C., Zhang J., Moore J. (2005) Evaluation of bond strength between pavement layers. National Center for Asphalt Technology, NCAT Report 05-08

[42] Romanoschi S.A., Metcalf J.B. (2002). The characterization of pavement layer interfaces. Proceedings of the 9th International conference on asphalt pavements, Copenhagen

[43] Mohammad, L., Elseifi, M.A., Bae, A., Patel, N., Button, J., \& Scherocman, J. A. (2012) Optimization of tack coat for HMA placement . NCHRP report 712

[44] Zofka A., Maliszewski M., Bernier A., Josen R., Vaitkus A., Kleizienė R. (2015) Advanced Shear Tester for Evaluation of Asphalt Concrete Under Constant Normal Stiffness Conditions. RMPD 16 (sup1): 187-210. doi: 10.1080/14680629.2015.1029690

[45] Zahw M. A. (1995) Development of testing framework for evaluation of rutting resistance of asphalt mixes. PhD Thesis, Carleton University, Ottawa, Canada

[46] Choi, Y., Collop, A., Airey, G., Elliot, R. (2005). A comparison between interface properties measured using the Leutner test and the torque test. Journal of Association of Asphalt Paving Technologists 74E. ISSN 1553-5576

[47] Tran Q-T., Toumi A., Granju J.-L. (2006) Experimental and numerical investigation of the debonding interface between an old concrete and an overlay. Materials and Structures 39(3): 379-389.

[48] Turatsinze A., Beushausen H., Gagné R, Granju J.-L., Silfwerbrand J, Walter R. (2011) 'Chapter Debonding'. State-of-the-Art Report of the RILEM Technical Committee 193-RLS Series, Bissonnette B., Courard L., Fowler, D.W. Granju, J.-L, (Eds), vol. 3,107-139

[49] Tran Q-T., Toumi A., Turatsinze A. (2011) Delamination of thin bonded cement-based overlays: analytical analysis. Materials and Structures 44(1): 43-51

[50] Hun M., Chabot A., Hammoum F. (2012) A four point bending test for the bonding evaluation of composite pavement. Proceedings of the 7th Rilem Int. Conf. on Cracking in Pavements, June 20-22, Delft, The Netherlands. RILEM Bookseries 4: 51-60. doi: 10.1007/978-94-007-4566-7_6

[51] Chabot A., Hun M., Hammoum, F. (2013) Mechanical analysis of a mixed mode debonding test for "composite" pavements. Construction and Building Materials 40: 10761087. doi: 10.1016/j.conbuildmat.2012.11.027

[52] Barman, M., Vandenbossche, J., Mu, F., Gatti, K. (2011) Development of design guide for thin and ultra-thin concrete overlays of existing asphalt pavements, task 1 report : Compilation and review of existing performance data and information. Technical report, FHWA Pooled Fund Study TPF 5-65

[53] Chen, Y., Tebaldi, G., Roque, R., and Lopp, G. (2013). Development of a Composite Specimen Interface Cracking (CSIC) Test for Top-Down Cracking. Journal of Testing and Evaluation 41 (4): 625-634. doi: 10.1520/JTE20120002

[54] Destrée A., De Visscher J., Vanelstraete A. (2012) Evaluation of tack coat performance for thin and ultra-thin asphalt pavements. $5^{\text {th }}$ Eurasphalt \& Eurobitume Congress, 13-15th June 2012, Istanbul

[55] Raab C., Abd El Halim A. O., Partl M.N. (2011) Interlayer Bond Testing using a Model Material. Construction and Building Materials 26: 190-199. doi:10.1016/j.conbuildmat.2011.06.009

[56] Raab C., Partl M.N. (2010). Temperature dependency of interlayer shear testing. Transport Research Arena Europe TRA 2010, Brussels, Belgium 